\section{Hemorrhagic Septicemia in Asian Elephants Elephas maximus in Karnataka state, India}

\section{B.R. Harish ${ }^{1}$, B.M. Shivaraj ${ }^{2}$, B.M. Chandranaik ${ }^{2}$, M.D. Venkatesh ${ }^{2} \&$ C. Renukaprasad ${ }^{2}$}

1,2 Southern Regional Disease Diagnostic Laboratory (SRDDL), Institute of Animal Health and Veterinary Biologicals (IAH\&VB), Karnataka Veterinary, Animal and Fisheries Sciences University (KVAFSU), Hebbal, Bengaluru, Karnataka 560024, India Email: ${ }^{1}$ drharishnaik@gmail.com

Various infectious agents have been incriminated in causing diseases in wild animals, of which bacterial diseases are the most common occurrence and Hemorrhagic Septicemia (HS) or Pasturellosis has long been recognized as a serious disease. The disease was reported in wild ruminants viz. spotted deer, bighorn sheep, bison, barking deer, musk deer, as well as in lion, leopard and elephants in India and world wide (Ahmed 2001; Srivasatv 2003)

In view of the importance of $\mathrm{HS}$, the present investigation was carried out on Asian Elephants (Elephas maximus) in three national parks of Karnataka state, India

Clinical history: A male $3^{1 / 2}$ year old elephant belonging to the Mysore Zoo - Sri Chamarajendra Zoological Gardens was sick with symptoms of respiratory distress, frothy discharge from trunk; swelling under the abdomen and base of tail; and intermittent digestive disorders. The zoo veterinarian treated the elephant symptomatically. The animal was recumbent and died after a prolonged illness. Two other wild elephants belonging to the Nagarahole National Park and Bhadra Wildlife Sanctuary were found dead in the forest. The local veterinarian conducted the post-mortems and collected clinical samples for laboratory investigations.

Gross findings: The following gross findings were observed in all three carcasses: the carcasses were found to be weak, debilitated with hemorrhagic conjunctiva, the bronchi and bronchioles were filled with frothy mucus plug, the heart showed various degrees of hemorrhages over the endocardium

Date of publication 26 March 2009

ISSN 0974-7907 (online) | 0974-7893 (print)

\section{Editor: Jacob V. Cheeran}

\section{Manuscript details:}

Ms \# 01778

Received 18 May 2007

Final revised received 08 December 2007

Finally accepted 21 July 2008

Citation: Harish, B.R., B.M. Shivaraj, B.M. Chandranaik, M.D. Venkatesh \& C. Renukaprasad (2009). Hemorrhagic Septicemia in Asian Elephants Elephas maximus in Karnataka state, India. Journal of Threatened Taxa 1(3): 194195.

Copyright: (C B.R. Harish, B.M. Shivaraj, B.M. Chandranaik, M.D. Venkatesh \& C. Renukaprasad 2009. Creative Commons Attribution 3.0 Unported License. JoTT allows unrestricted use of this article in any medium for non-profit purposes, reproduction and distribution by providing adequate credit to the authors and the source of publication.

\section{OPEN ACGESS | FREE DOWNLOAD}

with edematous atrial wall, the liver was congested and hard in consistency, the spleen showed hemorrhagic spots and congestion, the esophagous, stomach and, intestines showed edematous thickening with hemorrhages in the mucosal wall, and the kidney showed perirenal edema, subcapsular hemorrhages, and highly congested medulla.

Microbiological examinations: Impression smears of lung and heart blood revealed bipolar characteristic pasturella organisms (Image 1) by direct microscopic examination. Pure colonies of Pasturella multocida were obtained in heart blood cultured on blood agar. Mice inoculation study also confirmed the presence of pasturella species. No other causal agents were observed.

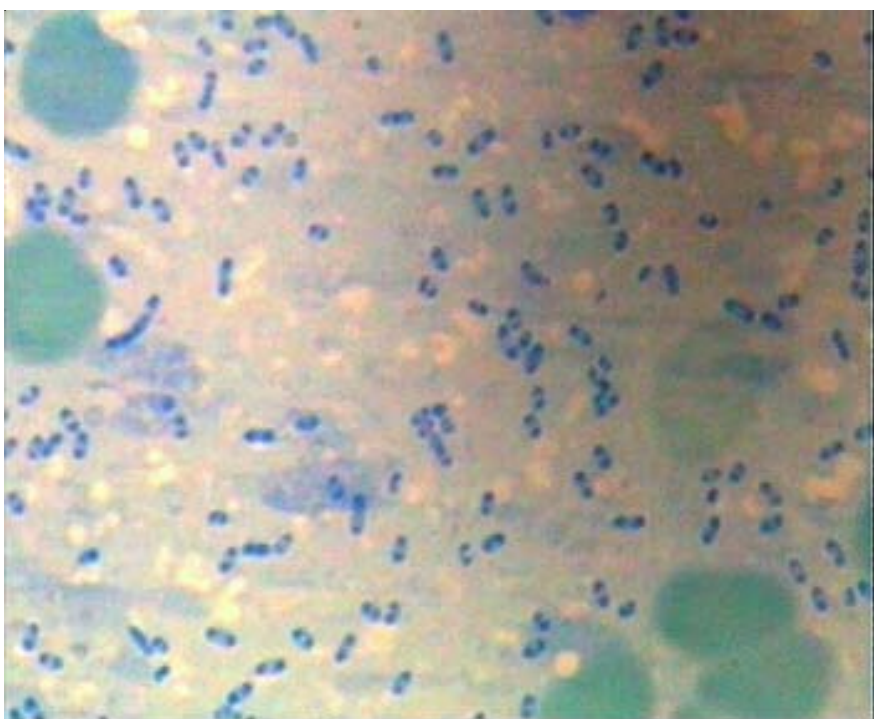

Image 1. Higher magnification of lung impression smear showed bipolar characteristic Pasteurella sp.

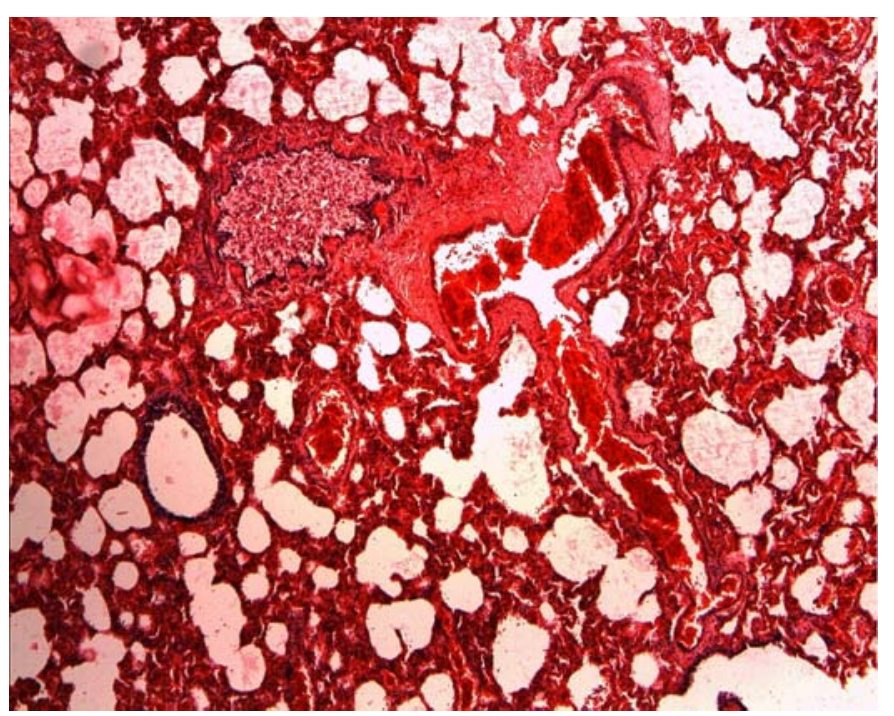

Image 2. Lung showing wide spread vascular damage; aggregation of inflammatory cells predominantly neutrophils and severe thickening of interalveolar septa. Occasionally fibrin deposition observed 


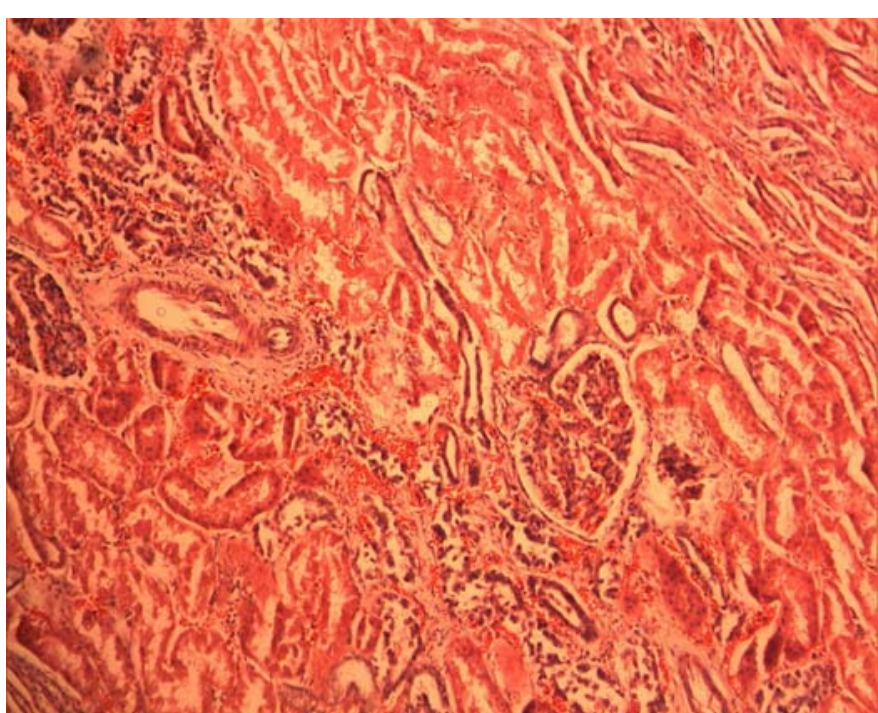

Image 3. Kidney revealed extensive vascular damage, tubules showed degenerative changes, characterized by tubular epithelial desquamation along with glomerular capillary degeneration

\section{Histopathological changes}

Lung: Section of the lungs showed congestion, edema, patchy areas of collapse and emphysema. Distention of interalveolar septa with infiltration of inflammatory cells predominantly neutrophils. The connective tissue surrounding the blood vessels was thickened. In addition, alveolar edema and occasional hemorrhages were noticed in the alveoli and throughout the parenchyma of lung (Image 2).

Liver: Periportal thickening due to fibrous tissue proliferation, bileduct epithelial hyperplasia and fibrous tissue proliferation around the central vein were predominant. Focal collection of inflammatory cells predominantly consisted of mononuclear cells and neutrophils.

Kidney: Tubules showed degenerative changes, characterized by tubular epithelial desquamation and lumen filled with eosinophilic debris. Glomerular capillary degeneration, periarterial sclerosis with thickening of the kidney capsule was noticed (Image 3).

Heart: Evidence of diffuse hemorrhages with focal necrosis of the muscle fibers (Image 4).

Spleen: Section of the spleen showed hemorrhages, lymphoid depletion and mild connective tissue proliferation.

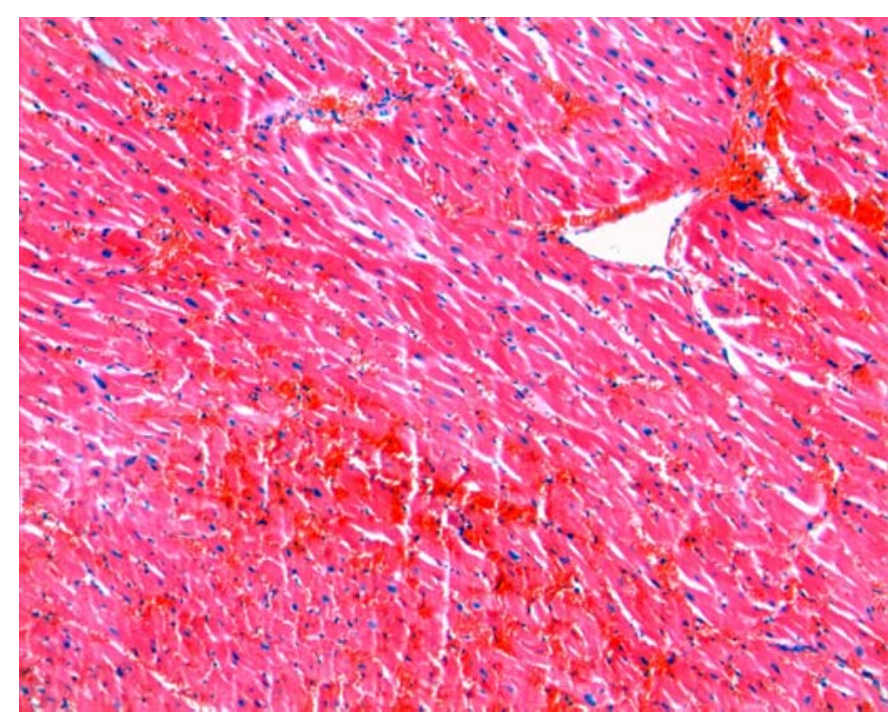

Image 4. Heart showing wide spread vascular damage, evidence of diffuse hemorrhages with focal necrosis of the muscle fibers.

Intestine: Vasculature appeared to be congested with evidence of hemorrhages. Disruptive changes were noticed in the tips of the villi epithelium.

Based on the clinical signs, gross and microscopic lesions, biochemical and mouse inoculation studies, it can be concluded that the death of the three elephants could be due to Pasturella species. The report of deaths due to HS in elephants was in accordance with Chandrashekharan (2002), and Srivasatv (2003).

\section{References}

Ahmed, N. (2001). Health management of free ranging wild animals. Intas Polivet 2(11): 182-186.

Chandrasekaran, K. (2002). Specific diseases of Asian elephants. Journal of Indian Veterinary Association VII(3): 31-34.

Shrivastav, A.B. (2003). History of Wildlife Diseases with Particular Reference To India. National Symposium On Basic Patholgy And Animal Diseases - A Need For Fresh Approach In Indian Scenario And XX Annual Conference Of Indian Association Of Veterinay Pathologists, Jabalpur, 142-147. 